\title{
Micro/nano-structured superhydrophobic surfaces in the biomedical field: part I: basic concepts and biomimetic approaches
}

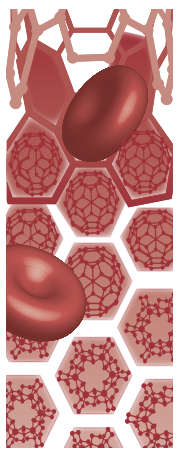

Inspired by natural structures, great attention has been devoted to the study and development of surfaces with extreme wettable properties. The meticulous study of natural systems revealed that the micro/nano-topography of the surface is critical to obtaining unique wettability features, including superhydrophobicity. However, the surface chemistry also has an important role in such surface characteristics. As the interaction of biomaterials with the biological milieu occurs at the surface of the materials, it is expected that synthetic substrates with extreme and controllable wettability ranging from superhydrophilic to superhydrophobic regimes could bring about the possibility of new investigations of cell-material interactions on nonconventional surfaces and the development of alternative devices with biomedical utility. This first part of the review will describe in detail how proteins and cells interact with micro/nano-structured surfaces exhibiting extreme wettabilities.

Keywords: bioinspired $\bullet$ biomimetic $\bullet$ cell adhesion $\bullet$ cell proliferation $\bullet$ contact angles

- micro/nano-roughness $\bullet$ nature $\bullet$ protein adsorption $\bullet$ superhydrophilic $\bullet$ superhydrophobic

- surfaces • tissue engineering • wettability

The surface of the biomaterials plays a relevant role in determining the outcome of the interactions between the materials and the biological environment. The properties of the surfaces manage the deposition of biomolecules and microorganisms, as well as the adhesion, spreading, growth, migration and position of cells [1]. Significant properties of the surfaces of biomaterials include chemistry, elasticity, morphology and wettability. The manipulation of these characteristics has emerged as an important point of research in materials science in order to achieve sets of properties that are more appropriate for specific biological functions. In this part of the review, we will focus our attention on the pertinence of surfaces wettability in the biomedical field, specifically looking at the level of the interactions of cells and proteins with superhydrophobic/superhydrophilic platforms.

Surfaces with extreme wettabilities combined with low/high adhesive properties have been biomimetized after an intensive investigation to understand how nature has developed surfaces with such characteristics. The ability to synthetically produce such kinds of structures has attracted huge interest due to their potential for applications in microfluidic, controlled drug delivery and self-cleaning surfaces [2].

Wettability is currently evaluated by the static and dynamic behavior of a liquid droplet over a surface [3]. The apparent contact angle (CA' $\theta$ ), which is the angle formed by a liquid droplet on the threephase contact line (Figure 1A), characterizes the static behavior. The dynamic comportment is evaluated by the sliding angle ( $\alpha$; the inclination angle of the surface that cause the droplet to roll off) and CA hysteresis ( $\mathrm{CAH}$; the difference between advancing and receding CAs; Figure 1B). Based on these definitions, the surface is classified as wetting if the CA is lower than $90^{\circ}$ and as nonwetting if the $\mathrm{CA}$ is higher than $90^{\circ}$. When the liquid droplet is water, the
Ana Catarina Lima ${ }^{1,2}$ \& João F Mano*,1,2

'3B's Research Group-Biomaterials, Biodegradables andBiomimetics,

University of Minho, Headquarters of the EuropeanInstitute of Excellence on Tissue Engineering and Regenerative Medicine, AvePark, 4806-909 Taipas, Guimarães, Portugal

${ }^{2}$ ICVS/3B's - PT Government Associate Laboratory, Braga/Guimarães, Portugal *Author for correspondence: jmano@dep.uminho.pt

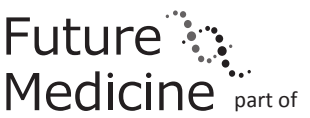
fsg 
(A)

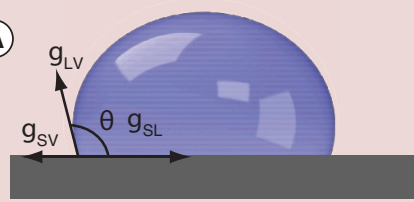

(B)

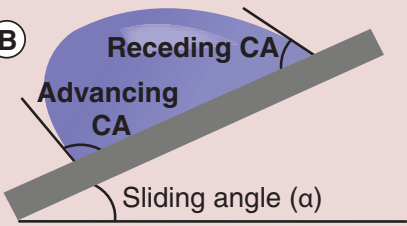

(C)

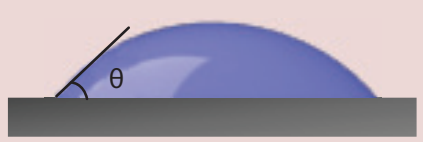

Hydrophilic

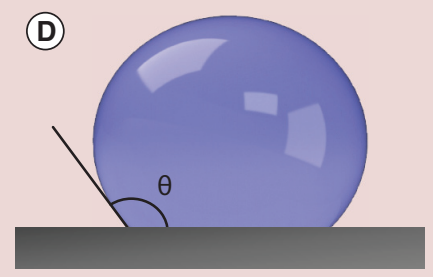

Hydrophobic

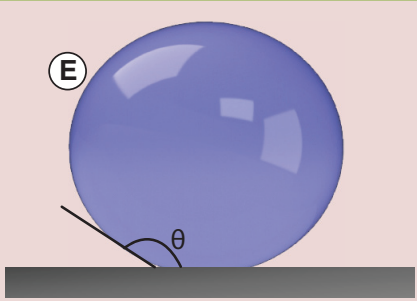

Superhydrophobic

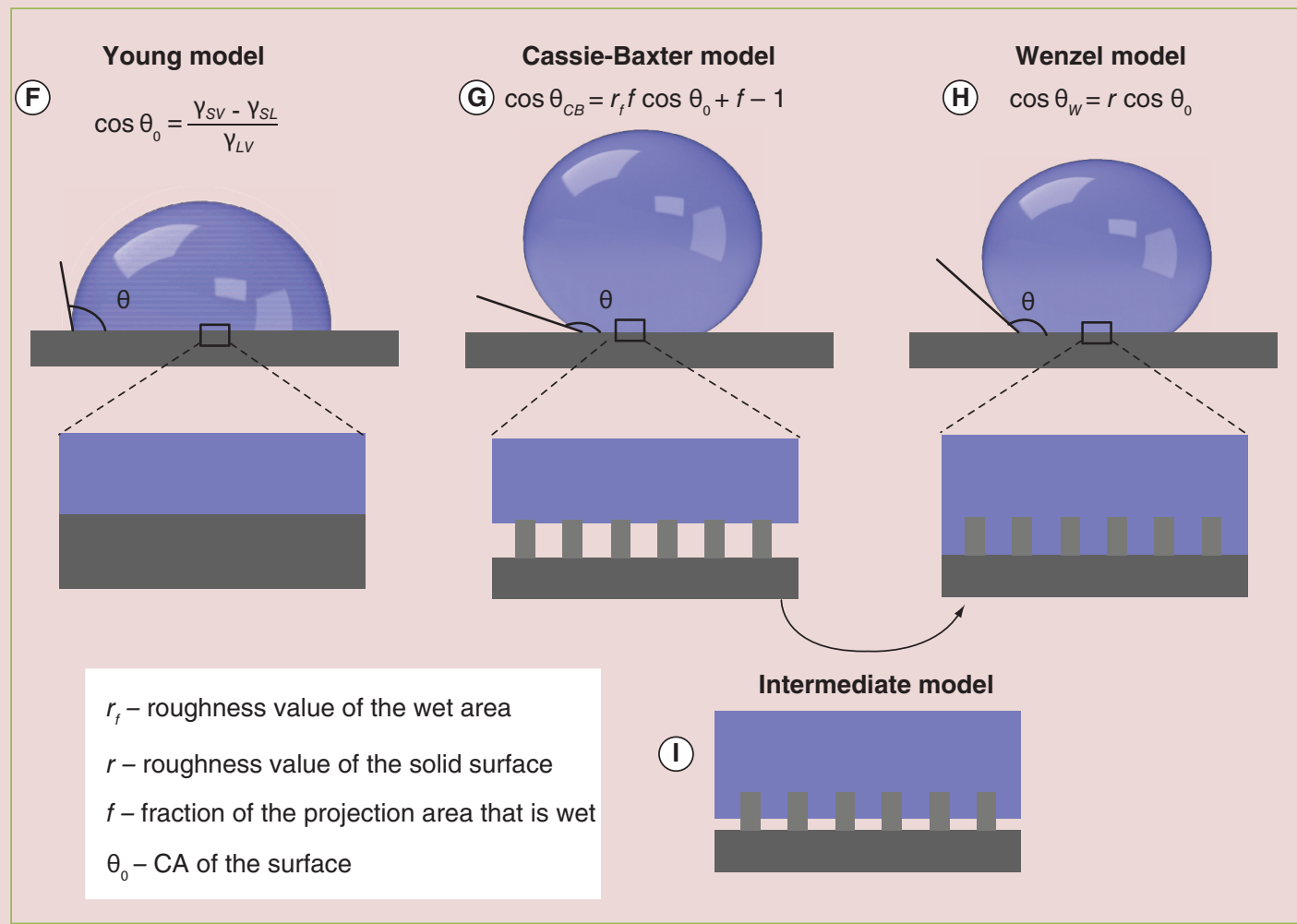

Figure 1. Liquid droplets contacting solid surfaces form a contact angle $\boldsymbol{\theta}$ where 3 different interfaces are involved: solid/liquid (SL), liquid/vapor (LV) and solid/vapor (SV). The wettability of the surfaces is evaluated regarding the static and dynamic behavior of the droplets. (A) The static conditions comprise the apparent contact angle $(C A, \theta)$ which is the angle formed by a liquid droplet on the three phase contact lines. (B) The dynamic behavior is related to the sliding angle $(\alpha)$, this means the inclination angle of the surface which cause the droplet roll off; and the contact angle hysteresis $(\mathrm{CAH})$ determined by the difference between advancing CA and receding CA. Depending on the CA formed by a water droplet, the surfaces can be: (C) hydrophilic $\left(\theta<90^{\circ}\right)$; (D) hydrophobic $\left(\theta>90^{\circ}\right)$; (E) superhydrophobic $\left(\theta>150^{\circ}\right)$; and superhydrophilic (nonrepresented). Developed mathematical models could explain the droplet-surface interaction: (F) the Young's model relates the CA to interfacial tensions (energies, $\gamma$ ) in an ideal smooth surface; (G) Cassie-Baxter, (H) Wenzel's, and (I) the intermediate models have in consideration the effect of surface roughness.

CA: Contact angle. 
surfaces are called 'hydrophilic' and 'hydrophobic', respectively (Figure $1 C \& D$ ) [2]. In terms of energy, wettable surfaces exhibit high values that may vary between 500 and $5000 \mathrm{mNm}^{-1}$. Conversely, nonwettable surfaces are characterized by low surface energy with values ranging from 10 to $50 \mathrm{mNm}^{-1}$ [2].

One type of nonwettable surfaces that have been thoroughly explored in recent years are the superhydrophobic surfaces, characterized by exhibiting water CAs greater than $150^{\circ}$ (Figure 1E). There are two types of superhydrophobic surfaces differing in their adhesive properties. If the $\mathrm{CAH}$ is lower than $5^{\circ}$, the surface is nonadhesive, and the droplets of water roll off at a minimum inclination. Otherwise, if the $\mathrm{CAH}$ is higher than $5^{\circ}$, the water droplet stay preferentially adhered onto the surface.

The cooperation of the topographic design of the roughness with the intrinsic chemistry of the materials defines the wettability of the surfaces. In terms of topography, the existence of micro/nano-roughness significantly affects the wettability properties of the materials, since they increase the CA in low-energy surfaces and decrease it in high-energy surfaces [4]. The most relevant traditional parameters for characterizing the roughness of the surfaces (root mean square, correlation length and fractal dimension) have been reviewed elsewhere [5], where the influences of such parameters on the wetting state of hierarchical natural structures was also detailed.

In the case of low-adhesive superhydrophobic surfaces, the existence of a hierarchical roughness from the nano- to the micro-scale leads to minimal contact between the liquid and the surface. The water dispensed onto this type of platform acquires an almost spherical shape in order to minimize the energy, being suspended on the top of the micro/nanostructures that compose the surface, and at minimal inclinations, the droplets roll off [6]. In high-adhesive surfaces, the droplets also acquire a near-spherical shape due the presence of micro/nano-structures, but do not roll off easily. The different design of the surface features, when compared with low-adhesive surfaces, explains this different behavior. In general, the high-adhesive superhydrophobic surfaces present a larger pitch that allows the liquid to impregnate into the microstructures, but only partially within the nanostructures [7].

Physical models have been proposed in order to rationalize the effect of roughness and surface energy. The Young model (Figure 1F) describes the contact between a sessile drop onto rigid, homogeneous, flat and inert surfaces - ideal smooth surfaces. Wenzel's model (Figure $1 \mathrm{H}$ ) proposed an equation for predicting the influence of the surface rough- ness or morphology on the CA [3,4]. In this model, it is assumed that water penetrates into the grooves of the surface structures. Otherwise, the CassieBaxter model (Figure 1G) depicts the case in which the air bubbles entrapped inside the grooves of the topographic features prevent the water penetration, meaning that the liquid is only in contact with the top of the exposed protrusions. Transitions from the Cassie-Baxter to the Wenzel state may occur and an intermediate state may be achieved (Figure 11). This shift is usually caused by the nonhomogeneous distribution of structural and chemical features, by pressure of the droplets against the surface, or even by the impact when the liquid is dropped [4].

Currently, it is well known that the chemistry and the presence of micro/nano-structures constitute key parameters directly influencing the performance of implantable materials due to the interaction with blood or extracellular matrix proteins, as well as with the different cell types - such cross-talk between biomaterial surfaces and all biological components will strongly dictate the integration or rejection of the devices [8]. The surface of the materials constitutes the first line of contact with the biological parts, not only in implanted materials, but also in devices for diagnosis, treatment and diseases prevention.

In the last 5-10 years, much work has been performed in the development and application of superhydrophobic surfaces but, until now, to the best of our knowledge, a compilation of the most recent applications in the biomedical field has never been presented. We will first overview the different repellent surfaces found in nature, detailing the relationship between micro- and nano-structures and wettability. This section will be followed by a brief description of the recreation, at the laboratory scale, of the most relevant micro/nano-structured natural surfaces. This first part of the review will also highlight the interactions of the proteins and cells with micro- and nano-structured surfaces, whereas the most important medical applications of the superhydrophobic surfaces will be compiled in part II of this review.

\section{Surface micro/nano-structures $\&$ the special wettability of natural systems}

Natural systems offer us a huge number of examples of surfaces with very peculiar properties in terms of structures and functions. The perfect combination of both structure and function allows for the achievement of maximal performance within a certain role. Exploring plants and animals enables us to find a huge diversity of complex surfaces (Figure 2).

The most well-known and studied natural superhydrophobic structure is the isotropic surface of 


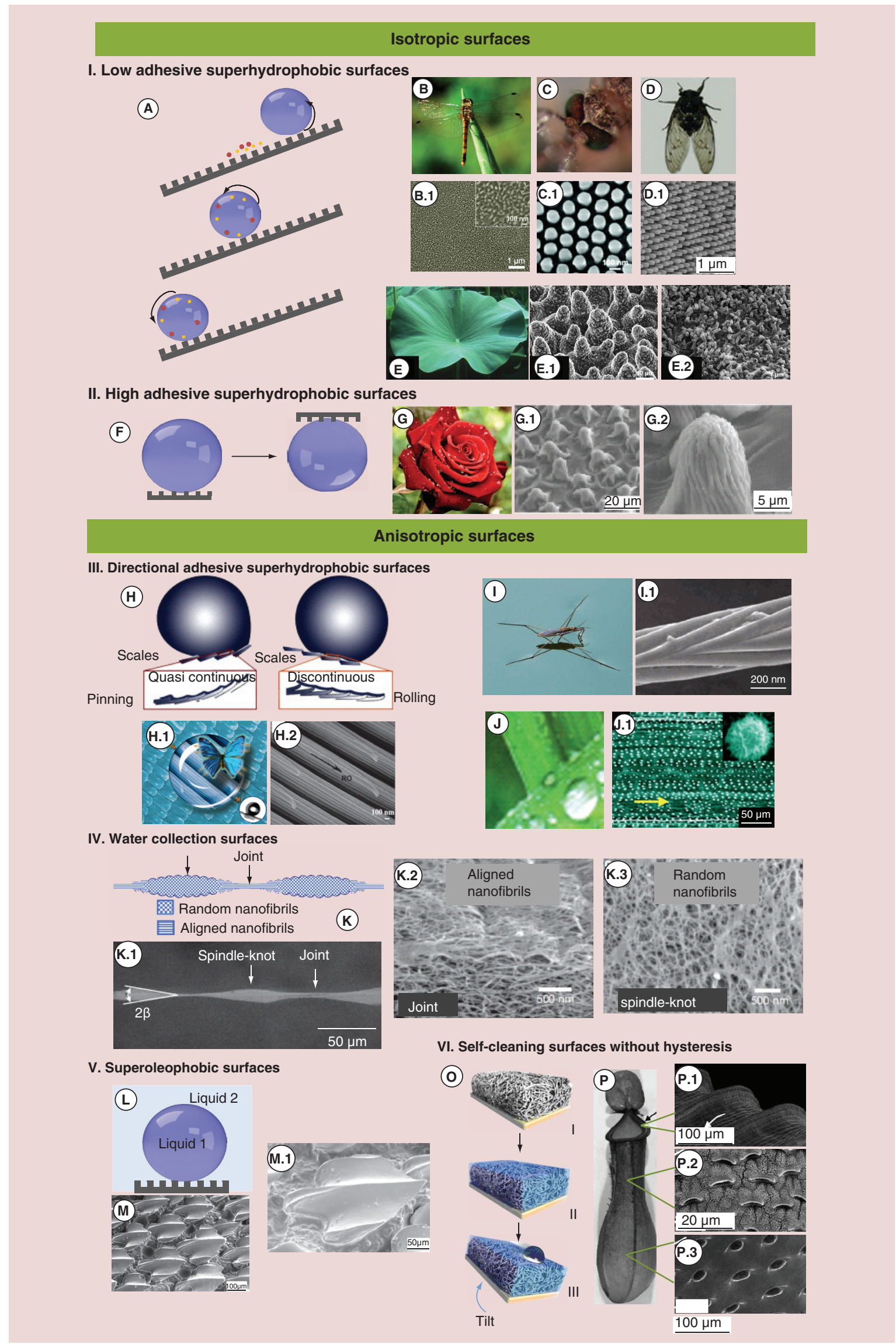


Figure 2. Examples of isotropic and anisotopic micro/nano-structured surfaces found in nature (see facing page). Superhydrophobic isotropic surfaces are the most well studied structures and include (I) low adhesive and (II) high adhesive structures. Low adhesive superhydrophobic surfaces exhibiting (A) self-cleaning effect comprise (B \& B.1) insect wings, (C \& C.1) mosquito eyes, (D \& D.1) cicada wings and (E \& E.1-2) lotus leaf, where the water droplets roll off easily when the surface is slightly inclined. (F) High adhesive surfaces as the case of (G \& G.1-2) some rose petals have the capacity to retain the water droplets without roll off. Anisotropic natural structures exhibit directional adhesion (III). Representative examples are (H \& H.1-2) butterfly wings, water stride legs (I \& I.1) and rice leaves (J \& J.1). Other substrates could be used: (IV) to collect water; such as spider silk; (V) repel oil products when surrounded by (L) liquids as it is the case of (M \& M.1) shark skin; or even have (VI.O) self-cleaning properties where the droplets slip without rolling off, (P \& P.1-3) the Nepenthes pitcher plant being the most-well-known case. The scanning electron microscopy images of each natural system show that independently of the general behavior of the surfaces, they are composed by a hierarchical arrangement of micro and nano topographic structures.(B), (B.1), (G) and (I), reproduced with permission from [9]; (C \& C.1) reproduced with permission from [10]; (D, D.1 \& H.1) reproduced with permission from [11]; (E \& E.1-2) reproduced with permission from [12]; (G.1-2) reproduced with permission from [7]; (H \& H.2) adapted with permission from [13]; (I.1) reproduced with permission from [14]; (J \& J.1) reproduced with permission from [15]; (K \& K.1-3) adapted with permission from [16]; (M \& M.1) reproduced with permission from [17]; (O) reproduced with permission from [18]; (P \& P.1-3) adapted with permission from [19].

the lotus leaf (Figure 2E). The extreme water-repellent properties of such biosurfaces results from the dualscale hierarchical roughness, which is composed of papillose epidermal cells (Figure 2E.1), with sizes consisting of between 5 and $10 \mu \mathrm{m}$, covered by epicular waxes of approximately $150 \mathrm{~nm}$ (Figure 2E.2) [20]. When water droplets fall on the lotus leaf, they are only in contact with the hydrophobic wax crystals on the top of the papillae, meaning that the contact between droplets and the surface is minimal. The hierarchical structure of the leaf surface is one of the promoters of CAs higher than $150^{\circ}$ and a CAH lower than $5^{\circ}$. Such characteristics are crucial for the selfcleaning effect; the droplets easily roll off the leaf, carrying off contaminating particles (Figure 2A) [21]. Lotus leaves are thus classified as nonadhesive superhydrophobic surfaces.

An opposite effect is displayed by the rose petals, which are also superhydrophobic but have the ability to retain small water droplets without them rolling off when the surface is inclined or even tilted down (Figure $2 \mathrm{~F} \& \mathrm{G}$ ) [7]. The adhesive effect derives from their array of micropapillae, comprising diameters of approximately $16 \mu \mathrm{m}$ and heights of approximately $7 \mu \mathrm{m}$ (Figure 2G.1), with nanoscaled cuticular folds of approximately $730 \mathrm{~nm}$ in width on their top (Figure 2G.2) [22]. When compared with the lotus leaf surface, rose petals have higher distances between the microstructures. The liquid droplets deposited onto such structures penetrate into the microscale grooves and only partially between the nanostructures due to the formation of air gaps (Wenzel model) [7,23], resulting in a strong adhesion between the liquid and the rose petal surface.

Nature has also developed anisotropic surfaces in which the droplets of water can roll off following a preferential direction dictated by the structural features. Remarkable examples are butterfly wings
(Figure $2 \mathrm{H}$ ), water strider legs (Figure $2 \mathrm{I}$ ) and rice leaves (Figure 2J). In the case of butterfly wings, they have multiscale structures composed of aligned shingle-like scales (Figure 2H.1). Flexible nanotips on the top of the ridging nanostrips are arranged in a particular direction (Figure 2H.2). Such oriented structured surfaces allow for the adhesion and directional moving of the liquid on the solid surface. Similar behaviors can be seen in rice leaves [36].

Another type of natural surface enables the collection of water from the atmosphere in order to ensure the survival of the biological system under extreme drought environments. The most well-known cases are the desert beetles, cactus spines and spider silk (Figure 2K \& K.1). For example, in the case of spider silk, two main driving forces act simultaneously, enabling the propelling of water droplets through the fibers: the differences of surface free energy along the fibers; and the pressure differences between the inner and exterior of the water droplets. The differences in free energy and droplet pressure are caused by the intercalary spindle knots composed of random nanofibrils (Figure 2K.2) and joints composed of aligned nanofibrils (Figure 2K.3). The droplets are condensed and targeted in order to surround the spindle knots [16].

The previously described examples areair/liquid/solid systems, meaning interactions of liquids with solid-air surfaces. However, there are liquid/liquid/solid natural systems that have recently attracted researchers' attention. Such solid surfaces (e.g., shark skin [Figure 2M], fish scales and clam shells) present liquid repellency when involved in a liquid environment (Figure 2L). The surfaces are maintained as clean when surrounded by oil-polluted water and exhibit antibioadhesion properties. A detailed study of shark skin revealed the presence of a kind of tooth-like scale array (dermal denticles) with longitudinal grooves aligned according to the water flow direction (Figure 2M.1). Due to the 
movement of water through the surface structures, shark skin has low drag and prevents the adhesion and growth of marine organisms, as well as the contamination by oily substances [37]. The understanding of the underlying phenomenology of such natural surfaces could have relevance in the biomedical area, as it could help in the design of new antifouling substrates, channels and tubes with low dragging in fluid transport, or surfaces with particular biological effects upon contact with cells and tissues.

Although different to the lotus leaves, Nepenthes pitcher plants (Figure 2P \& P.1-3) present a very peculiar self-cleaning effect. The liquid droplets slip instead of roll along the surface (Figure 20). This type of plant is well known due to its capability to capture and digest arthropods, absorbing nutrients from them, after their slipping through the walls of the plant's cavities [38]. Depending on the nutritional requirements of the plant, the inner surface of the pitcher switches from a wet state, during which the insects slip, to a dry state, in which anchorage points are provided in order to prevent the insects from sliding. The wettability is thus a key factor in the survival of these plants. In this natural system, the micro-roughness does not increase hydrophobicity, as occurs in lotus leaves. The organized ridges that compose the roughness of the pitcher act as capillary forces, inducing the rapid spreading of the water droplets along the wet surface, even against gravitational forces [39].

\section{Biomimetic surfaces}

During the course of evolution, biological systems have achieved distinct intelligent processes and properties relevant for their survival. The capacity for adaptation of natural systems in order to circumvent adverse conditions has inspired engineers to develop new functional materials [40]. Detailed analysis of the previously described natural structures revealed that intrinsic material properties and micro/nano-topographic structures play a crucial role in the wettable nature of surfaces. These unique and versatile properties have led to the design and creation of novel superantiwetting surfaces, such as superhydrophobic [41], superoleophobic [42,43], superamphiphobic (or superomniophobic) [44], smart switchable [45], anisotropic/water-collecting [46] and slippery liquid-infused porous surfaces (SLIPS; Figure 3) [18].

The design of artificial bioinspired surfaces involves up to five steps: the search and subsequent detailed study of the unique wetting phenomena of the natural structure; the study of the correlation between multiscale structures and the wettability properties; the design and synthesis of adequate molecules; the design of the multiscale structures; and surface fabrication $[11,40]$.
The lotus leaf has been the main inspiring natural source for developing artificial nonadhesive superhydrophobic surfaces. Two strategies have been traditionally used: the creation of micro/nano-roughness onto low-surface-energy materials; or the modification of micro/nano-rough surfaces with materials of low surface energy [47]. Combining physical and chemical methods, namely lithography, vapor deposition, plasma technique, sol-gel processing and layer-by-layer methods, among others (as reviewed elsewhere [48]), two general designs may be obtained: surfaces with micro/nano-random structures [24,49-52] and surfaces with controlled topographic features [53-56]. A recent review reported the latest advances in the general design of artificial superhydrophobic surfaces [41]. When the obtained micro/nano-structured surfaces do not achieve the desired CA or sufficiently low surface energy to perform a certain function, other strategies were developed in order to circumvent this issue. In general, postfabricated surfaces could be treated with self-assembled monolayers of alkanothiols, organic silanes, fatty acids or aromatic azide or spin-coated with perfluorononane [48].

Usually, the organic solvents are polar and present lower surface tensions than water (e.g., the surface tension of $\mathrm{n}$-hexadecane is $27.5 \mathrm{mNm}^{-1}$ and of $\mathrm{n}$-decane is $23.8 \mathrm{mNm}^{-1}$ vs water, with a surface tension of $72.8 \mathrm{mNm}^{-1}$ ) [57], which makes the production of surfaces that repel organic liquids more difficult than superhydrophobic surfaces. Nevertheless, superoleophobic surfaces may also be obtained that combine micro/nano-roughness and coatings using materials with very low surface energy [58-61].

Most of the developed artificial superoleophobic surfaces are oil repellent when surrounded by liquids (liquid/liquid/solid systems). However, the evolution in surfaces preparation enabled the production of solid/air/liquid superoleophobic systems. High-adhesive properties (equivalent to water adhesion onto rose petals) of artificial superoleophobic platforms make it difficult for organic droplets to roll off, consequently preventing the self-cleaning effect [58,62-64]. Artificial self-cleaning surfaces with the capability to repel organic substances were created using fish scales [37,65] and Nepenthes pitcher plants [18] as sources of inspiration. The amazing slippery properties of Nepenthes pitcher plants led to the development of four-phase systems, namely air/liquid/liquid/solid surfaces, denominated as 'SLIPS' [18]. SLIPS-based systems are composed of micro/nano-structures embedded with a lubricant fluid. In contrast to lotus leaves, these natural structures demonstrated slipperiness, without hysteresis, of pure or even complex liquids, such as blood and oil, ice, dust, insects and even bacteria $[66,67]$. The lubricant 


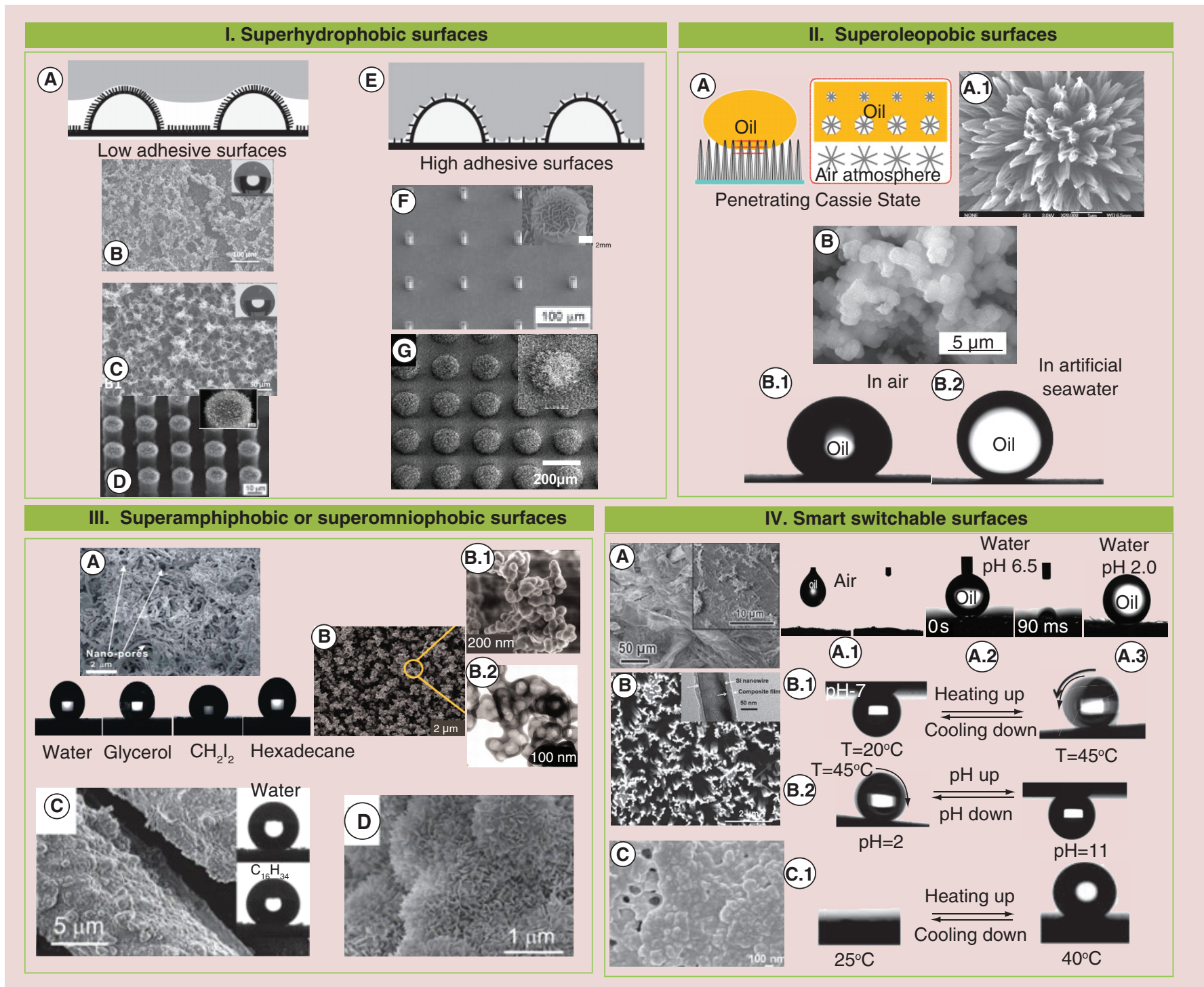

Figure 3. Examples of micro/nano-structured artificial surfaces produced by inspiration from natural systems. (I.) Examples of superhydrophobic surfaces with low adhesion where the liquid droplets are suspended (I.A) on the top of the nanostructures: (I.B) polystyrene; (I.C) copper and (I.D) a micropatterned Si replica. (I.E) Examples of high adhesive superhydrophobic surfaces, where the water enters through the micro exposed elements but air pockets prevent the penetration into the nano roughness are: (I.F) micropatterned epoxy resin coated with nanostructures of n-hexatriacontane and (I.G) hierarchical hairy carbonaceous fibers deposited on micropatterned Si. (II.) Superoleophobic surfaces of $\mathrm{Cu}(\mathrm{OH})_{2}$ nanoneedle arrays capable to control the oil adhesion depending on the nanostructures at the surface and the preloads on (II.A \& A.1) the oil droplet and (II.B \& B.1-2) aluminum coated with a polyelectrolyte multilayer treated with perfluorooctanoate which repels oil in dry and wet environments. (III) Surfaces capable to repel both water and organic liquids are named superamphiphobic or superomniophobic. Examples are: (III.A) coralline-like structured surfaces obtained by spraying nanocomposites of fluorinated multiwalled carbon nanotubes and fluorinated polyurethane; (III.B) surfaces obtained by carbon nanospheres deposition, coated with a silica shell, (III.B.1) in which the carbon core was removed by calcination, (III.B.2) revealing a structured silica coating with holes; (III.C) cotton textiles coated with micro- and nano-silica particles; and (III.D) etched and fluorinated aluminum. (IV) Smart surfaces capable of changing their behavior when subjected to a certain stimulus have also been developed: (IV.A \& A.1-3) textile surfaces capable of switching from superoleophilic to superoleophobic when immersed in a certain aqueous medium; (IV.B) hierarchical structured surfaces coated with poly(N-isopropylacrylamide-co-acrylic acid) (PNIPAAm-CO-AAC) which are adhesive or nonadhesive depending on (IV.B.1) the temperature and (IV.B.2) on the pH of the droplet; and (IV.C) silicon coated with PNIPAAM, surfaces that, depending on the temperature, are superhydrophilic or superhydrophobic (IV.C.1). (I.A), (I.E \& I.F) reproduced with permission from [7]; (I.B \& I.C) reproduced with permission from [24]; (I.D) reproduced with permission from [25]; (I.G) reproduced with permission from [26]. (II.A \& II.A.1) reproduced with permission from [27]; (II.B \& II.B.1-2) reproduced with permission from [28]. (III.A) reproduced with permission from [29]; (III.B \& III.B.1-2) reproduced with permission from [30]; (III.C) reproduced with permission from [31]; (III.D) reproduced with permission from [32]. (IV.A \& IV.A.1-3) adapted with permission from [33]; (IV.B \& IV.B.1-2) adapted with permission from [34]; (IV.C \& IV.C.1) adapted with permission from [35]. 
forms a continuous film, meaning that the friction on the micro/nano-structures of the solid surface is very low. The film has the same function as the air pockets on lotus leaves [18]. In addition, after physical damage, SLIPS have the capability of self-healing [18]. By simply selecting a lubricant that is immiscible with water and oils [68], SLIPS may exhibit omniphobic properties [44].

Functionalized surfaces capable of switching their wettability in a reversible way as a response to an external stimulus (e.g., temperature, $\mathrm{pH}$, photon energy, electric field, humidity or electrochemical and chemical treatments) [2] have been proposed due to increasing interest in such surfaces for a wide variety of applications. An overview of this kind of surface is reported elsewhere [21]. However, irreversible modifications of the physicochemical properties of super-repellent surfaces could also be important for their application or integration into other devices. Accurate, controllable, cost-effective and fast techniques for performing surface modifications/patterning are challenging [69]. The possibility of tailoring optical, mechanical, chemical and wettable traits, among others characteristics, in limited, and preselected areas have allowed for the production of arrays that could be used as microfluidic devices and as screening chips. A detailed description of the applications of patterned superhydrophobic surfaces in the biomedical field will be reported in the part II of this review. In general, there are two possibilities for controlling the wettability of the surfaces: adjusting the organization and spatial distribution of the micro/nano-roughness; and modifying the chemical properties of the micro/nano-structured surfaces by exposing hydrophilic or hydrophobic groups or even bonding/adsorbing biochemical cues [70]. For example, the increment of oxygen-rich groups is a pathway for increasing the wettability of surfaces. The treatments of poly(L-lactic acid) (PLLA) and polystyrene (PS) superhydrophobic surfaces by plasma and ultaviolet/ ozone exposure have been demonstrated to be useful for controlling surface wettability [50,71-72]. Such treatments induced the formation of oxygen-containing species $(\mathrm{C}-\mathrm{O}, \mathrm{C}=\mathrm{O}$ and $\mathrm{O}-\mathrm{C}=\mathrm{O})$ that are responsible for increasing the surface free energy and, consequently, making the surface more wettable independently of the micro/nano-roughness. In both of the PLLA and PS cases, depending on the exposure time, the wettability of the surfaces was controlled within extreme ranges of CAs in an accurate manner. The use of masks (generally platforms with predefined holes of controlled geometries) is a straightforward approach to confining the desired modifications to preselected areas, enabling the production of patterned superhydrophobic surfaces with the most favorable design for the proposed application.
Bearing in mind that smart and bioinstructive substrates have been widely used in the biomedical field [73,74], we hypothesize that the combination of such features with extreme wettability could bring new possibilities of developing devices with unique features for both in vivo and ex vivo applications.

\section{Interactions of cells \& proteins with superhydrophobic surfaces}

The interaction between cells and materials at the chemical or even physical level is extremely important for the success of therapeutic/diagnosis strategies involving implantable biomaterials [75]. Conceptually, four stages are involved in cell-material interactions: adsorption of proteins from the biological milieu; cell perception and sensing of the adsorbed cues; cell attachment; and, finally, the spreading or other biological consequences of the cells.

Studies on cell-material interactions on surfaces with varied wettable properties have largely been focused within the hydrophilic-hydrophobic range $\left(20^{\circ}<\mathrm{CAs}<110^{\circ}\right)$. However, curiosity regarding the biological response beyond such CAs intervals has been encouraging the development of new approaches in order to obtain further insights into such complex phenomena.

The unique properties of the superhydrophobic surfaces triggered increasing interest in their application in the biomedical field. However, the biological performance of such types of surfaces needs to be understood in maximum detail. Only a very few studies have been published reporting the interactions of proteins or cells with such micro/nano-structured highly repellent surfaces. As explained in the previous sections of this article, the properties of the superhydrophobic surfaces are related to their micro/nanostructured surface and surface chemistry, with both being properties that are directly correlated with wettability. Therefore, it is critical to understand the effects of these characteristics in an individual manner on protein and cell behavior. The current status of this field will be described in detail in the following sections.

\section{Protein adsorption}

The first event when any material is implanted into the human body is the coating of the surface by proteins present in the blood or interstitial fluids (extracellular matrix proteins). Hydrophobic interactions, electrostatic attraction, van der Waals forces and hydrogen bonding are involved in protein adsorption [76,77]. In a general way, proteins tend to preferentially adsorb strongly onto nonpolar than polar surfaces, high surface tension than low surface tension surfaces and 


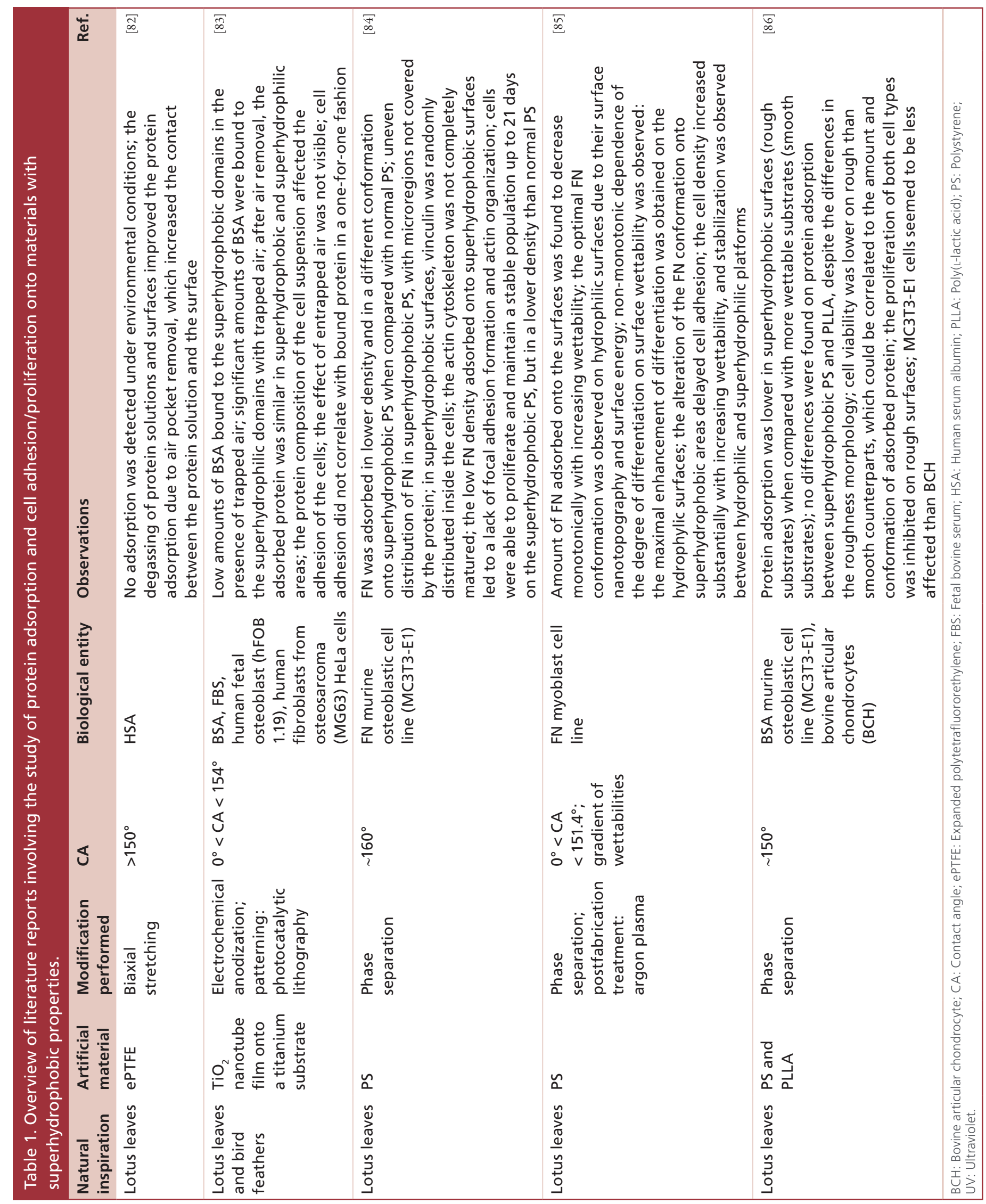




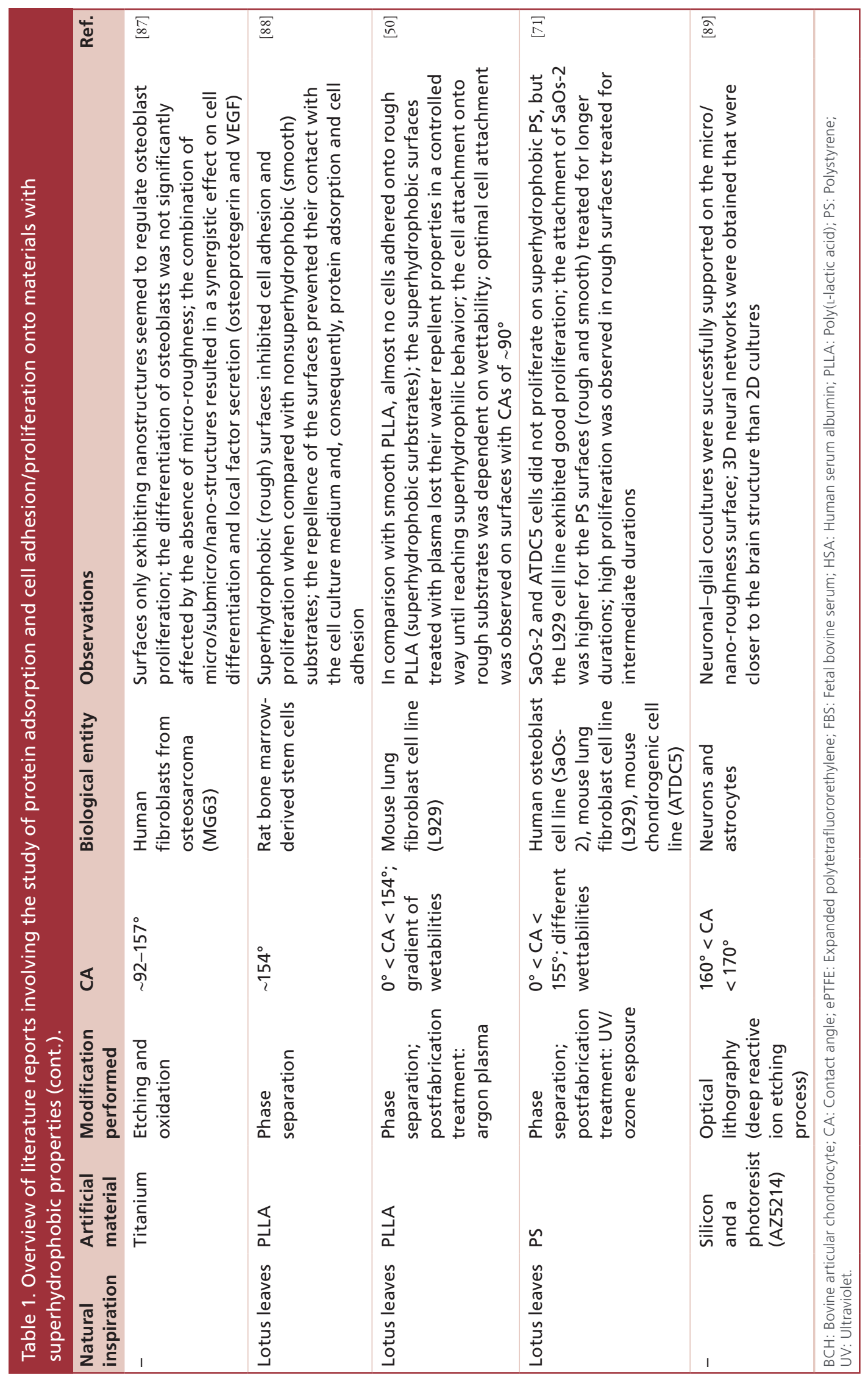


charged than noncharged surfaces [78]. The destabilization of the proteins caused by nonpolar surfaces facilitates protein structural reorganization and reorientation, leading to strong interprotein and proteinsurface interactions [79]. In addition, it has also been demonstrated that topography has a significant influence on protein adsorption [76]. The adsorption can be more pronounced onto the nanostructured surfaces due to the existence of higher numbers of active sites as a consequence of a higher surface area. However, the existence of roughness at the micro- or nano-scale is closely related to surface wettability, which could have an independent effect on the change in the exposed surface area. Several studies have been presented focusing the the interactions of proteins and cells with micro/nano-structured surfaces with extreme repellent properties, as has recently been reviewed elsewhere [80,81]. Table 1 compiles the studies reported in the literature focusing on the interactions of proteins and cells with superhydrophobic surfaces. The adsorption of human serum albumin was studied in expanded polytetrafluororethylene (ePTFE), a commonly used hydrophobic material in biomedical applications. ePTFE may become superhydrophobic upon stretching due to the formation of a fibrillar surface structure [82]. Under ambient conditions, no protein adsorption was measured on the superhydrophobic material. However, when the ePTFE surfaces were degassed, significant protein adsorption was detected. The air entrapped in the features of the ePTFE surperhydrophobic surface prevented intimate contact with human serum albumin solutions and consequently low protein adsorption. Huang et al. confirmed the effect of trapped air on protein adsorption using surfaces coated with $\mathrm{TiO}_{2}$ nanotubes [83]. The surfaces were patterned with superhydrophobic/superhydrophilic areas. The air trapped in $\mathrm{TiO}_{2}$ nanotubes prevented the contact of the protein solution with superhydrophobic domains. The protein adsorption was inhibited in such regions when compared with superhydrophilic regions. However, this was reversed when the surfaces were sonicated and the air trapped in the nanostructures was displaced: more protein was detected in superhydrophobic than in superhydrophilic areas. Once again, the extraction of the gas induces the transition from the Cassie-Baxter to the Wenzel model, in which the protein solution could make contact with a major surface area. Cassie-Baxter-based superhydrophobic surfaces are then considered to be resistant to protein adsorption due to the trapped air between the micro/nano-stuctures, which acts as a 'virtual layer' and impedes subsequent platelet and cell adhesion.

FN adsorption was analyzed on PS superhydrophobic surfaces (a standard material used in cell cultures) [84]. The physical modification of the PS platforms did not affect the chemical properties of the surface. Again, lower density of FN with a changed conformation was found on micro/nano-structured surfaces when compared with smooth platforms. As a consequence, the cell behavior was significantly affected [84]. Micro/nano-structured PS superhydrophobic surfaces were then chemically modified by plasma treatment in order to investigate the influence of wettability on FN adsorption and conformation [85]. As expected, the amount of FN adsorbed decreased monotonically with increasing wettability, since this protein tends to be adsorbed in greater amounts onto hydrophobic surfaces. However, the conformation did not follow the same tendency. In micro/nano-rough surfaces with hydrophilic properties, the protein adopted a more favorable conformation than in hydrophobic or superhydrophilic areas. This observation highlights a very important point that we consider worthy of being studied in more detail: besides the total protein content, surfaces with extreme wettabilities could direct distinct conformational changes in the adsorbed proteins. Protein adsorptions onto two different superhydrophobic materials obtained by the same methodology were compared [86]. Superhydrophobic PS and PLLA were prepared using a phase separation method. The different physical properties of the polymers induced the appearance of completely different topographical structures. Once again, the nonwettable properties of the rough surfaces prevented the contact between the bovine serum albumin solution and the surfaces, decreasing the amount of protein adsorbed. No differences were observed between the two materials upon examination. Such results suggest that the general wettability characteristics of a surface have a stronger influence on protein adsorption than its specific chemical and topographical properties.

As demonstrated by all of the above described reports, the composition, orientation and conformation of adsorbed proteins could be determinants of cell attachment. The adsorbed proteins should exhibit appropriate conformations in order to maintain their biological functions, particularly the capacity to be recognized by cells. In order to improve the performance of micro/nano-structured superhydrophobic surfaces, surface modifications may be advantageous, namely the covalent grafting of key cell-adhesive groups or the modification of surface chemistry by the increment of the number of oxygen-rich species. In the opposite case of superhydrophilic surfaces, the higher adsorption of water produces repulsive forces on the proteins, preventing their deposition and, consequently, the adhesion of the cells. 


\section{Cells interactions}

Cells sense the surrounding environment through membrane ion channels and a series of receptors. Integrins are the main constituents that are responsible for the establishment of connections between the cells and surfaces [90], as well as controlling cell shape changes, proliferation and cell migration. Integrins are composed of two noncovalently associated subunits $(\alpha$ and $\beta$ ) integrated in the cell membrane. There are several types of $\alpha$ and $\beta$ subunits and their combination determines the ligand specifity of the integrin. Although it is known that the complex process of cell-biomaterial interaction occurs after protein adhesion, the mechanism itself is not completely understood. However, it is understood that this is dependent on the surface properties (i.e., wettability, flexibility, topography, surface charge, chemistry and mechanical properties) of the type of cell and on the presence of proteins or other biochemical cues $[72,75,80,91]$.

Since topography has a great influence on cell behavior, data have been reported on cell interactions with micro/nano-surface structures such as grooves, ridges, steps, pores, wells and nodes at micro- or nano-scales [92]. Micro- and nano-patterned surfaces have been studied in order to understand the effect of topography on cell behavior. An overview of the potential of chemical and topographical effects on cell-material cross-talk has been reported elsewhere [75]. It is very well known that material surface chemistry, topography and, consequently, wettability influence cell stages, namely differentiation, proliferation, matrix production, cell morphology and orientation [93]. One particular example is the influence of surface characteristics on the osteointegration of implanted materials. For example, Gittens et al. showed that combined micro/submicro-roughness and a high density of nanostuctures enhanced osteoblast differentiation and new bone formation in vitro, provided better bone-to-implant contact in vivo and improved clinical rates in wound healing [87,94]. Such kinds of hierarchical structures mimic the structures of the bone during the remodeling process. The resorption of lacunae performed by osteoclasts consists of microscale pits $(\sim 100 \mu \mathrm{m}$ in diameter and $50 \mu \mathrm{m}$ in depth) composed of submicro-scale structures and nano-scale features created by fibers of collagen [87]. Due to the synergistic effect of the combination of structures with different sizes in osteointegration, efforts have been conducted in order to obtain tailored hierarchically structured surfaces with appropriated chemical and surface energy properties [87]. Regarding the general properties of the superhydrophobic surfaces, we hypothesize interesting possibilities of using such substrates in bone tissue engineering purposes.

Similarly to that described for protein adsorption, the elevated repellency of superhydrophobic surfaces could prevent the contact of the cells with the entire surface area. Consequently, the cells only have the chance to adhere onto the peaks of the micro/nanostructures exposed on the materials, limiting the adhesion and proliferation of the cells. On the other hand, the super-repellent surfaces exhibiting a Wenzel state should permit the penetration of the liquids into the micro-roughness, providing more points for protein and cell adhesion [91]. Therefore, any interpretation of the performance of cells adhering to superhydrophobic surfaces should require a careful characterization of how liquids and proteins interact with the micro/nano-features of the substrates.

The study of the interactions between bone marrow-derived stem cells and PLLA biodegradable superhydrophobic membranes exhibiting random micro/nano-surface structures showed an inhibitory effect on cell adhesion and proliferation when compared with smooth PLLA [88]. Song et al. demonstrated that fibroblast-like cells exhibited similar behavior when cultured onto the same PLLA surfaces [50]. However, when the surfaces were treated with argon plasma, the hydrophilicity increased due to the formation of oxygen-rich groups on the surface, and cell attachment was improved. Controlling the plasma treatment, gradients of wettabilities were produced allowing the control of cell adhesion in the space [50]. Based on this, and considering that PS is the standard material used in cell culture, Oliveira et al. studied the cell adhesion/proliferation onto superhydrophobic PS, which was also obtained by a phase separation method [71]. A vast range of wettabilities was obtained by treating the surfaces with ultraviolet/ozone exposure for different durations. The treatment did not significantly modify the nano/micro-surface structures, but introduced oxygen-containing groups onto the surface in a similar fashion to PLLA treated with argon plasma described above. The interaction of different cell types with smooth and rough PS surfaces was extensively investigated [71]. For short culturing time periods ( $4 \mathrm{~h}$ and 2 days), the studied cell types presented a rounder shape in superhydrophobic PS than after 6 days, where a few SaOs-2 (osteoblast-like cells) and ATDC5 (chondrocyte-like cells) were distributed. In smooth PS, all of the cell types presented a normal morphology. The cell number over time was significantly high for L929 (fibroblasts) cells than the other cell types, probably due to their intrinsic higher proliferation rate. In addition, it was observed that 
SaOs-2 and ATDC5 cells did not proliferate onto rough or smooth PS when compared with normal PS used in cell culture plates. $\mathrm{SaOs}-2$ cell adherence and proliferation was also studied on ultraviolet/ozone PS surfaces [71]; such cells showed a preference to hydrophilic environments independently of the roughness of the surface. Such results were also confirmed in another study [86]. In that work, the responses of a cell line (murine osteoblastic cell line MC3T3-E1) and a primary cell culture (bovine articular chondrocytes isolated from the cartilage of calf legs) seeded onto two different superhydrophobic surfaces (PS and PLLA) were studied in detail. The different roughnesses of both surfaces reduced the affinity of both types of cells, inhibiting proliferation, and both cell types exhibited similar behaviors. It was concluded that the overall wettability was the main factor affecting the cell behavior, not simply the polymer chemistry or surface topography [86].

The aforementioned examples confirmed the huge effect of wettability on cell behavior. Biological behavior varied according to the cell type. The interaction of primary neurons with superhydrophobic surfaces composed of nanopatterned pillars obtained by lithography was studied in order to evaluate their ability for 3D network formation [89]. Neurons presented an enhanced survival rate when compared with 2D standard cultures, which are flat surfaces. They adhered to the pillar sidewalls and pulled between the structures in a suspending position, developing a mature network. In this particular case, the superhydrophobic surface acts as a 3D scaffold. It would be interesting to perform in vitro toxicity assays on such structures, as they could constitute a good model for studying cancer cell differentiation and migration in a more realistic fashion.

The previously described works demonstrate that the control of the adsorbed biomolecules and the spatial distribution of adhered cells are highly dependent on the combination of the chemical and structural properties of the surface. Taking advantage of the performance of the micro/nano-structures' superhydrophobic surfaces, implantable materials and other kind of devices were developed. An overview of the most relevant applications in the biomedical field will be presented in the second part of this article [Lima AC, Mano JF. Micro/nano-structured superhydrophobic surfaces in the biomedical field: part II: applications overview (2015), Submitted].

\section{Conclusion}

This article provided a very concise compilation of the main characteristics of natural structures with extreme repellent properties. Surface topography and chemistry are the key factors for achieving such behavior. Inspired by the properties of natural surfaces, artificial superhydrophobic platforms have been developed through different processes, combining micro/nano-features and low-surface-energy materials. The unique properties of the superhydrophobic surfaces have been explored regarding their influences on protein adsorption and cell adhesion and proliferation. Although being in a quite early stage, such studies were designed to help us to understand the performance of such platforms in a biological context. Superhydrophobic surfaces have been shown to be resistant to protein adsorption; but such an effect could be dependent on how liquids interact with the micro/nano-texture (e.g., Cassie-Baxter vs Wenzel models or self-cleaning vs adhesive surfaces). Compared with smooth substrates, the adhesion and proliferation of the cells were also affected when they were seeded onto such micro/nano-rough surfaces, and also when such surfaces were subjected to further chemical modifications. The possibility of manipulating the wettability of the micro/nanostructured surfaces both in all extended surface areas and in confined sites by using appropriate masks has been extending the employment of superhydrophobic surfaces in the biomedical field. The most relevant examples will be compiled in the part II of this article.

\section{Future perspective}

The behavior of natural repellent systems has inspired the development of artificial superhydrophobic surfaces; however, their development has largely focused on materials for industrial applications or the improvement of simple tasks in daily life. In the last few years, the first reports of these systems associated with biomedical applications have appeared, but the studies related to the biological integration of superhydrophobic surfaces are still in the early stages. More investigation into superhydrophobic surface interactions with biological entities and detailed explanations of the phenomena that occurr at such kinds of interfaces may constitute a driving force to extending future research. Since protein adsorption is a dynamic process involving attachment, detachment and conformational changes, the performance of superhydrophobic surfaces when studied in dynamic conditions (flowing environments) could provide a more realistic view of these types of interactions. Until now, only static conditions have been reported in the literature.

A deep understanding of the protein-superhydropobic surfaces interactions is important for the development of biomaterials, since protein adsorption 
is related to bacterial adhesion and the formation of thrombi. In particular, more investigation is required into the conformational organization of adsorbed proteins on surfaces exhibiting wettabilities ranging from the superhydrophilic to the superhydrophobic range.

Many methodologies have been used in order to modify the surfaces of such materials. However, most of the materials that have been changed to achieve superhydrophobic behavior are not able to be used in applications inside the human body due to their nonbiocompatible properties or even the instability of the surfaces, which may cause adverse responses when applied for long periods of time. Advances in materials science research have improved parameters such as the stability, robustness and durability of surfaces, but more work still needs to be carried out in order to obtain high-performance and biocompatible superhydrophobic platforms.

We also expect major advances in the industrial production of superhydrophobic surfaces, including large areas with homogeneous properties and patterned platforms with areas of contrasting wettabilities. Once again, the stability of the surfaces in order to prevent or avoid an intermediate wettable state, which results from the transition from a Cassie-Baxter to a Wenzel stage, constitutes a challenge. For example, the design of topographical structures with greater high or optimized geometries could be a strategy for achieving more stable surfaces. Such progress should be accompanied by the latest developments of micro/nano-fabrication technologies.

Moreover, taking into account the fact that superomniophobic surfaces are composed of materials and roughnesses that induce even lower surface energies when compared with superhydrophobic surfaces, the behavior of these surfaces should also be explored in a biological context in order to obtain a preliminary overview of bodily acceptance when the surface of biomaterials shows the capacity to repel water and organic (e.g., lipidic) molecules.

\section{Financial \& competing interests disclosure}

AC Lima is grateful for financial support from Portuguese Foundation for Science and Technology (FCT) through the grant SFRH/BD/71395/2010 (under the scope of QRENPOPH - Tipologia 4.1 - Formação Avançada subsidized by European Social Found as well as by national funds of MEC). The authors also acknowledge the national funds from the FCT in the scope of project PTDC/CTM-BIO/1814/2012. The authors have no other relevant affiliations or financial involvement with any organization or entity with a financial interest in or financial conflict with the subject matter or materials discussed in the manuscript apart from those disclosed.

No writing assistance was utilized in the production of this manuscript.

Executive summary

\section{Surfaces}

- Surface properties of materials play crucial roles in biomaterial acceptance.

- The manipulation of chemistry, elasticity, morphology and wettability is extremely important to achieving the set of properties that is most appropriate for a particular biomedical role.

- The topographic design and the intrinsic chemistry of materials define the wettability of surfaces.

Surface micro/nano-structures $\&$ the special wettability of natural systems

- Natural systems exhibit a huge diversity of complex surfaces at both structural and functional levels.

- All highly repellent natural surfaces have in common the hierarchical roughness composed of a rearrangement of micro- and nano-structures at the surface.

- The low- and high-adhesive properties of the superhydrophobic surfaces are dictated by the different designs of the topographical features, with the most well-studied cases being those of the lotus leaf and rose petals, respectively.

Biomimetic surfaces

- The design of new surfaces is greatly inspired by the properties of the surfaces found in natural systems.

- Superhydropobic, superoleophobic, superamphiphobic, smart switchable, water collecting and slippery liquid-infused porous surfaces have been recreated in the laboratory and extensively characterized.

- Depending on the used micro/nano-fabrication methodologies, random or controlled designs may be produced on material surfaces.

Interactions of the cells \& proteins with superhydrophobic surfaces

- Cell-material interactions occur at the surface level and are defined by the physical and chemical superficial properties.

- Protein adsorption, cell adhesion and proliferation are biological events that are greatly influenced by the micro/nano-roughness and wettability behavior of surfaces. 


\section{References}

Papers of special note have been highlighted as:

- of interest; $\bullet \bullet$ of considerable interest

1 Skorb EV, Andreeva DV. Surface nanoarchitecture for bioapplications: self-regulating intelligent interfaces. Adv. Funct. Mater. 23(36), 4483-4506 (2013).

2 Verplanck N, Coffinier Y, Thomy V, Boukherroub R. Wettability switching techniques on superhydrophobic surfaces. Nanoscale Res. Lett. 2(12), 577-596 (2007).

3 Bellanger H, Darmanin T, Taffin de Givenchy E, Guittard F. Chemical and physical pathways for the preparation of superoleophobic surfaces and related wetting theories. Chem. Rev. 114(5), 2694-2716 (2014).

4 Yan YY, Gao N, Barthlott W. Mimicking natural superhydrophobic surfaces and grasping the wetting process: a review on recent progress in preparing superhydrophobic surfaces. Adv. Colloid Interface Sci. 169(2), 80-105 (2011).

-. Review reporting the principles of wetting phenomena and an onverview of the methods used in the preparation of superhydrophobic surfaces.

5 Nosonovsky M, Bhushan B. Biologically inspired surfaces: broadening the scope of roughness. Adv. Funct. Mater. 18(6), 843-855 (2008).

6 Gao L, McCarthy TJ. The 'lotus effect' explained: two reasons why two length scales of topography are important. Langmuir 22(7), 2966-2967 (2006).

7 Bhushan B, Her EK. Fabrication of superhydrophobic surfaces with high and low adhesion inspired from rose petal. Langmuir 26(11), 8207-8217 (2010).

8 Yao X, Song Y, Jiang L. Applications of bio-inspired special wettable surfaces. Adv. Mater. 23(6), 719-734 (2011).

- Overview of the applications of repellent surfaces.

9 Zhang Y-L, Xia H, Kim E, Sun H-B. Recent developments in superhydrophobic surfaces with unique structural and functional properties. Soft Matter 8(44), 11217-11231 (2012).

10 Gao X, Yan X, Yao X et al. The dry-style antifogging properties of mosquito compound eyes and artificial analogues prepared by soft lithography. Adv. Mater. 19(17), 2213-2217 (2007).

11 Xia F, Jiang L. Bio-inspired, smart, multiscale interfacial materials. Adv. Mater. 20(15), 2842-2858 (2008).

12 Ensikat HJ, Ditsche-Kuru P, Neinhuis C, Barthlott W. Superhydrophobicity in perfection: the outstanding properties of the lotus leaf. Beilstein J. Nanotechnol. 2, 152-161 (2011).

13 Zheng Y, Gao X, Jiang L. Directional adhesion of superhydrophobic butterfly wings. Soft Matter 3(2), 178-182 (2007).

14 Gao X, Jiang L. Biophysics: water-repellent legs of water striders. Nature 432, 36 (2004).

15 Feng L, Li S, Li Y et al. Super-hydrophobic surfaces: from natural to artificial. Adv. Mater. 14(24), 1857-1860 (2002).

16 Zheng Y, Bai H, Huang Z et al. Directional water collection on wetted spider silk. Nature 463, 640-643 (2010).
17 Jung YC, Bhushan B. Biomimetic structures for fluid drag reduction in laminar and turbulent flows. J. Phys. Condens. Matter. 22, c035104 (2010).

18 Wong T-S, Kang SH, Tang SKY et al. Bioinspired self-repairing slippery surfaces with pressure-stable omniphobicity. Nature 477(7365), 443-447 (2011).

19 Koch K, Bhushan B, Barthlott W. Multifunctional plant surfaces and smart materials. In: Springer Handbook of Nanotechnology. Bhushan B (Ed.). Springer, Germany, 1399-1436 (2010).

20 Wang J, Chen H, Sui T, Li A, Chen D. Investigation on hydrophobicity of lotus leaf: experiment and theory. Plant Sci. 176(5), 687-695 (2009).

21 Anastasiadis SH. Development of functional polymer surfaces with controlled wettability. Langmuir 29(30), 9277-9290 (2013).

22 Feng L, Zhang Y, Xi J et al. Petal effect: a superhydrophobic state with high adhesive force. Langmuir 24(8), 4114-4119 (2008).

23 Bhushan B, Nosonovsky M. The rose petal effect and the modes of superhydrophobicity. Philos. Trans. A Math. Phys. Eng. Sci. 368(1929), 4713-4728 (2010).

24 Lima AC, Song W, Blanco-Fernandez B, Alvarez-Lorenzo C, Mano JF. Synthesis of temperature-responsive dextranMA/PNIPAAm particles for controlled drug delivery using superhydrophobic surfaces. Pharm. Res. 28(6), 1294-1305 (2011).

25 Koch K, Bushan B, Jung YC, Barthlott W. Fabrication of artificial lotus leaves and significance of hierarchical structure for superhydrophobicity and low adhesion. Soft Matter 5 , 1386-1393 (2009).

26 Zhao Y, Qin M, Wang A, Kim D. Bioinspired superhydrophobic carbonaceous hairy microstructures with strong water adhesion and high gas retaining capability. $A d v$. Mater. 25(33), 4561-4565 (2013).

27 Yao X, Gao J, Song Y, Jiang L. Superoleophobic surfaces with controllable oil adhesion and their application in oil transportation. Adv. Funct. Mater. 21(22), 4270-4276 (2011). Zhang G, Zhang X, Huang Y, Su Z. A surface exhibiting superoleophobicity both in air and in seawater. ACS Appl. Mater. Interfaces 5(13), 6400-6403 (2013).

29 Wang X, Hu H, Ye Q, Gao T, Zhou F, Xue Q. Superamphiphobic coatings with coralline-like structure enabled by one-step spray of polyurethane/carbon nanotube composites. J. Mater. Chem. 22(19), 9624-9631 (2012).

30 Deng X, Mammen L, Butt H-J, Vollmer D. Candle soot as a template for a transparent robust superamphiphobic coating. Science 335(6064), 67-70 (2012).

31 Leng B, Shao Z, de With G, Ming W. Superoleophobic cotton textiles. Langmuir 25(4), 2456-2460 (2009).

32 Yang J, Zhang Z, Xu X, Men X, Zhu X, Zhou X. Superoleophobic textured aluminum surfaces. New J. Chem. 35(11), 2422-2426 (2011).

33 Zhang L, Zhang Z, Wang P. Smart surfaces with switchable superoleophilicity and superoleophobicity in aqueous media: toward controllable oil/water separation. NPG Asia Mater. 4(2), e8 (2012). 
34 Cheng Z, Lai H, Du M, Zhu S, Zhang N, Sun K. Super-hydrophobic surface with switchable adhesion responsive to both temperature and $\mathrm{pH}$. Soft Matter 8(37), 9635-9641 (2012).

35 Sun T, Wang G, Feng L et al. Reversible switching between superhydrophilicity and superhydrophobicity. Angew. Chem. Int. Ed. Engl. 43(3), 357-360 (2004).

36 Bixler GD, Theiss A, Bhushan B, Lee SC. Anti-fouling properties of microstructured surfaces bio-inspired by rice leaves and butterfly wings. J. Colloid Interface Sci. 419, 114-133 (2014).

37 Bhushan B. Biomimetics inspired surfaces for drag reduction and oleophobicity/philicity. Beilstein J. Nanotechnol. 2, 66-84 (2011).

38 Bohn HF, Federle W. Insect aquaplaning: Nepenthes pitcher plants capture prey with the peristome, a fully wettable water-lubricated anisotropic surface. Proc. Natl Acad. Sci. USA 101(39), 14138-14143 (2004).

39 Bauer U, Federle W. The insect-trapping rim of Nepenthes pitchers: surface structure and function. Plant Signal. Behav. 4(11), 1019-1023 (2009).

40 Liu M, Wang S, Jiang L. Bioinspired multiscale surfaces with special wettability. MRS Bull. 38(05), 375-382 (2013).

- Compilation of the most important natural surfaces exhibiting hierarchical roughness on the surface.

41 Celia E, Darmanin T, Taffin de Givenchy E, Amigoni S, Guittard F. Recent advances in designing superhydrophobic surfaces. J. Colloid Interface Sci. 402, 1-18 (2013).

42 Xue Z, Liu M, Jiang L. Recent developments in polymeric superoleophobic surfaces. J. Polym. Sci. Part B Polym. Phys. 50 (17), 1209-1224 (2012).

43 Tuteja A, Choi W, Ma M et al. Designing superoleophobic surfaces. Science 318(5856), 1618-1622 (2007).

44 Kota AK, Choi W, Tuteja A. Superomniphobic surfaces: design and durability. MRS Bull. 38(05), 383-390 (2013).

45 Xin B, Hao J. Reversibly switchable wettability. Chem. Soc. Rev. 39(2), 769-782 (2010).

46 Hancock MJ, Demirel MC. Anisotropic wetting on structured surfaces. MRS Bull. 38(05), 391-396 (2013).

47 Ma M, Hill RM. Superhydrophobic surfaces. Curr. Opin. Colloid Interface Sci. 11(4), 193-202 (2006).

48 Zhang X, Shi F, Niu J, Jiang Y, Wang Z. Superhydrophobic surfaces: from structural control to functional application. J. Mater. Chem. 18(6), 621-633 (2008).

49 Qian B, Shen Z. Fabrication of superhydrophobic surfaces by dislocation-selective chemical etching on aluminum, copper, and zinc substrates. Langmuir 21(20), 9007-9009 (2005).

50 Song W, Veiga DD, Custódio CA, Mano JF. Bioinspired degradable substrates with extreme wettability properties. Adv. Mater. 21(18), 1830-1834 (2009).

51 Huang L, Lau SP, Yang HY, Leong ESP, Yu SF, Prawer S. Stable superhydrophobic surface via carbon nanotubes coated with a $\mathrm{ZnO}$ thin film. J. Phys. Chem. B 109(16), 7746-7748 (2005).
52 Li Y, Huang XJ, Heo SH et al. Superhydrophobic bionic surfaces with hierarchical microsphere/SWCNT composite arrays. Langmuir 23(4), 2169-2174 (2007).

53 Dorrer C, Rühe J. Some thoughts on superhydrophobic wetting. Soft Matter 5(1), 51-61 (2009).

54 Herbertson DL, Evans CR, Shirtcliffe NJ, McHale G, Newton MI. Electrowetting on superhydrophobic SU-8 patterned surfaces. Sensors Actuators A Phys. 130-131, 189-193 (2006).

55 Zhu L, Feng Y, Ye X, Zhou Z. Tuning wettability and getting superhydrophobic surface by controlling surface roughness with well-designed microstructures. Sensors Actuators A Phys. 130-131, 595-600 (2006).

56 Fürstner R, Barthlott W, Neinhuis C, Walzel P. Wetting and self-cleaning properties of artificial superhydrophobic surfaces. Langmuir 21(3), 956-961 (2005).

57 Zhang J, Wang A, Seeger S. Nepenthes pitcher inspired anti-wetting silicone nanofilaments coatings: preparation, unique anti-wetting and self-cleaning behaviors. Adv. Funct. Mater. 24(8), 1074-1080 (2014).

58 Xie Q, Xu J, Feng L et al. Facile creation of a super-amphiphobic coating surface with bionic microstructure. Adv. Mater. 16(4), 302-305 (2004).

59 Kiuru M, Alakoski E. Low sliding angles in hydrophobic and oleophobic coatings prepared with plasma discharge method. Mater. Lett. 58(16), 2213-2216 (2004).

60 Nicolas M, Guittard F, Géribaldi S. Synthesis of stable super water- and oil-repellent polythiophene films. Angew. Chem. Int. Ed. Engl. 45(14), 2251-2254 (2006).

61 Hoefnagels HF, Wu D, de With G, Ming W. Biomimetic superhydrophobic and highly oleophobic cotton textiles. Langmuir 23(26), 13158-13163 (2007).

62 Feng XJ, Jiang L. Design and creation of superwetting/antiwetting surfaces. Adv. Mater. 18(23), 3063-3078 (2006).

63 Darmanin T, Guittard F. Molecular design of conductive polymers to modulate superoleophobic properties. J. Am. Chem. Soc. 131(22), 7928-7933 (2009).

64 Zimmermann J, Rabe M, Artus GRJ, Seeger S. Patterned superfunctional surfaces based on a silicone nanofilament coating. Soft Matter 4(3), 450-452 (2008).

65 Liu M, Wang S, Wei Z, Song Y, Jiang L. Bioinspired design of a superoleophobic and low adhesive water/solid interface. Adv. Mater. 21(6), 665-669 (2009).

66 Epstein AK, Wong T-S, Belisle RA, Boggs EM, Aizenberg J. Liquid-infused structured surfaces with exceptional antibiofouling performance. Proc. Natl. Acad. Sci. USA 109(33), 13182-13187 (2012).

67 Stone HA. Ice-phobic surfaces that are wet. ACS Nano 6(8), 6536-6540 (2012).

68 Ma W, Higaki Y, Otsuka H, Takahara A. Perfluoropolyetherinfused nano-texture: a versatile approach to omniphobic coatings with low hysteresis and high transparency. Chem. Commun. (Camb.) 49(6), 597-599 (2013).

69 Manna U, Broderick AH, Lynn DM. Chemical patterning and physical refinement of reactive superhydrophobic surfaces. Adv. Mater. 24, 4291-4295 (2012). 
70 Arima $Y$, Iwata $H$. Effect of wettability and surface functional groups on protein adsorption and cell adhesion using well-defined mixed self-assembled monolayers. Biomaterials 28(36), 3074-3082 (2007).

71 Oliveira SM, Song W, Alves M. Chemical modification of bioinspired superhydrophobic polystyrene surfaces to control cell attachment/proliferation. Soft Matter 7, 8932-8941 (2011).

72 Neto AI, Custódio CA, Song W, Mano JF. High-throughput evaluation of interactions between biomaterials, proteins and cells using patterned superhydrophobic substrates. Soft Matter 7(9), 4147-4151 (2011).

-• Application of superhydrophobic-based chips to the study of cell adhesion in areas with different combinations of adsobed proteins.

73 Mano JF. Stimuli-responsive polymeric systems for biomedical applications. Adv. Eng. Mater. 10(6), 515-527 (2008).

74 Custódio CA, Reis RL, Mano JF. Engineering biomolecular microenvironments for cell instructive biomaterials. Adv. Healthc. Mater. 3(6), 797-810 (2014).

75 Alves NM, Pashkuleva I, Reis RL, Mano JF. Controlling cell behavior through the design of polymer surfaces. Small 6(20), 2208-2220 (2010).

- Compilation of the factors that could influence cell attachment and proliferation onto polymeric surfaces.

76 Akkas T, Citak C, Sirkecioglu A, Güner FS. Which is more effective for protein adsorption: surface roughness, surface wettability or swelling? Case study of polyurethane films prepared from castor oil and poly(ethylene glycol). Polym. Int. 62(8), 1202-1209 (2012).

77 Roach P, Farrar D, Perry CC. Interpretation of protein adsorption: surface-induced conformational changes. J. Am. Chem. Soc. 127(22), 8168-8173 (2005).

78 Rabe M, Verdes D, Seeger S. Understanding protein adsorption phenomena at solid surfaces. Adv. Colloid Interface Sci. 162, 87-106 (2011).

79 Anand G, Sharma S, Dutta AK, Kumar SK, Belfort G. Conformational transitions of adsorbed proteins on surfaces of varying polarity. Langmuir 26, 10803-10811 (2010).

80 Oliveira SM, Alves NM, Mano JF. Cell interactions with superhydrophilic and superhydrophobic surfaces. J. Adhes. Sci. Technol. 28(8-9), 843-863 (2014).

81 Song W, Mano JF. Interactions between cells or proteins and surfaces exhibiting extreme wettabilities. Soft Matter 9(11), 2985-2999 (2013).

82 Leibner ES, Barnthip N, Chen W et al. Superhydrophobic effect on the adsorption of human serum albumin. Acta Biomater. 5(5), 1389-1398 (2009).

83 Huang Q, Lin L, Yang Y, Hu R, Vogler EA, Lin C. Role of trapped air in the formation of cell-and-protein micropatterns on superhydrophobic/superhydrophilic microtemplated surfaces. Biomaterials 33(33), 8213-8220 (2012).

-• Study comparing the adsoprtion proteins and cell adhesion onto superhydrophilic and superhydrophobic surfaces in the presence or absence of air entrapped onto surface roughness.

84 Ballester-Beltrán J, Rico P, Moratal D, Song W, Mano JF, Salmerón-Sánchez M. Role of superhydrophobicity in the biological activity of fibronectin at the cell-material interface. Soft Matter 7(22), 10803-10811 (2011).

85 Cantini M, Sousa M, Moratal D, Mano JF, SalmerónSánchez M. Non-monotonic cell differentiation pattern on extreme wettability gradients. Biomater. Sci. 1(2), 202-212 (2013).

86 Lourenço BN, Marchioli G, Song W et al. Wettability influences cell behavior on superhydrophobic surfaces with different topographies. Biointerphases 7(1-4), 46 (2012).

87 Gittens RA, McLachlan T, Olivares-Navarrete R et al. The effects of combined micron-/submicron-scale surface roughness and nanoscale features on cell proliferation and differentiation. Biomaterials 32(13), 3395-3403 (2011).

- Study reporting the synergistic effects of micro-, submicroand nano-structures on the osteointegration of a device.

88 Alves NM, Shi J, Oramas E, Santos JL, Tomás H, Mano JF. Bioinspired superhydrophobic poly(L-lactic acid) surfaces control bone marrow derived cells adhesion and proliferation. J. Biomed. Mater. Res. A 91(2), 480-488 (2009).

89 Limongi T, Cesca F, Gentile F et al. Nanostructured superhydrophobic substrates trigger the development of $3 \mathrm{D}$ neuronal networks. Small 9(3), 402-412 (2013).

90 Hersel U, Dahmen C, Kessler H. RGD modified polymers: biomaterials for stimulated cell adhesion and beyond. Biomaterials 24(24), 4385-4415 (2003).

91 Stevens MM, George JH. Exploring and engineering the cell surface interface. Science 310(5751), 1135-1138 (2005).

92 Bettinger CJ, Langer R, Borenstein JT. Engineering substrate topography at the micro- and nanoscale to control cell function. Angew. Chem. Int. Ed. Engl. 48(30), 5406-5415 (2009).

- Presents the effects of different topographical designs on cell function.

93 Jayaraman M, Meyer U, Bühner M, Joos U, Wiesmann $\mathrm{H}-\mathrm{P}$. Influence of titanium surfaces on attachment of osteoblast-like cells in vitro. Biomaterials 25(4), 625-631 (2004).

94 Luz GM, Mano JF. Mineralized structures in nature: examples and inspirations for the design of new composite materials and biomaterials. Compos. Sci. Tecnol. 70(13), 1777-1788 (2010). 